САВЧЕНКО Ирина Александровна - доктор социологических наук, профессор кафедры философии, социологии и теории социальной коммуникации Нижегородского государственного лингвистического университета им. Н.А. Добролюбова (603155, Россия, г. Нижний Новгород, ул. Минина, 31а); профессор кафедры психологии и педагогики Нижегородской академии МВД РФ (603144, Россия, г. Нижний Новгород, Анкудиновское ш., 3; tеоsтасо@rambler.ru)

СНЕГИРЕВА Людмила Анатольевна - кандидат психологических наук, доцент; начальник кафедры психологии и педагогики Нижегородской академии МВД России (603144, Россия, г. Нижний Новгород, Анкудиновское ш., 3; sla_sq@таil.ru)

УСТИНКИН Сергей Васильевич - доктор исторических наук, профессор; декан факультета международных отношений, экономики и управления, профессор кафедры международных отношений и политологии Нижегородского государственного лингвистического университета им. Н.А. Добролюбова (603155, Россия, г. Нижний Новгород, ул. Минина, 31а); директор Приволжсккого филиала Федерального научно-исследовательского социологического центра РАН (603000, Россия, г. Нижний Новгород, пер. Холодный, 4; sv.ustinkin@gmail.com)

\title{
КОРРУПЦИОННАЯ ЛИЧНОСТЬ В ВОСПРИЯТИИ ПРОФЕССИОНАЛЬНЫХ И ВОЗРАСТНЫХ СОЦИАЛЬНЫХ ГРУПП
}

Аннотация. В статье представлен анализ результатов эмпирического исследования, направленного на изучение общественного восприятия личности коррупционера. Авторы отмечают, что среди большого числа работ, чьи авторы изучают различные аспекты феномена коррупции, можно обнаружить исследования, ориентированные на познание природы коррупционной личности, в Т.ч. С позиций ее восприятия другими людьми. В то же время различия, которые могут наблюдаться в отношении к коррупционерам в различных социальных группах, до сих пор не изучались ни в отечественной, ни в зарубежной науке. Авторы данной статьи проводят компаративный анализ восприятия коррупционной личности представителями различных возрастных и профессиональных групп: сотрудниками сферы правопорядка и лицами гражданских профессий, курсантами образовательных учреждений МВД России и студентами вузов. Предпринята попытка объяснения сходств и отличий в оценках личности коррупционера разными социальными группами.

Ключевые слова: коррупция, коррупционное поведение, личность коррупционера, социальная группа, сотрудники органов внутренних дел, лица гражданских профессий, курсанты

Введение. В различных областях социально-гуманитарного знания - от экономики и юриспруденции до социальной феноменологии и глубинной психологии наблюдаются определенные отличия в понимании личностных аспектов коррупционного поведения [Савченко, Снегирева, Устинкин 2018]. Авторы настоящей статьи исходят из положения, что неодинаковые подходы к коррупционному поведению могут наблюдаться не только в научном сообществе, но и в различных социальных группах, дифференцируемых, в частности, по возрастному и профессиональному признаку. Убежденность в том, что эффективность предупреждения и профилактики коррупционного поведения во многом зависит от понимания различных аспектов субъективного отношения разных категорий населения к значимым концептам современности [Савченко 2015], в т.ч. к личности коррупционера, стала принципиальным мотивом, побудившим авторов к эмпирическому поиску.

Дискуссия. На данный момент в эмпирической науке имеет место дискуссия, в которой обсуждаются различные стороны и причины формирования коррупционной личности. Исследователи нередко связывают коррупционное поведение с «ценностно-нормативными установками, формируемыми культурой» 
[Попов 2012], или же рассуждают о коррупционной личности в категориях нравственной порочности и «социального зла» [Горобова 2015]. Развивая идею нравственного субстрата коррупционного поведения, исследователи устанавливают взаимосвязи между коррупциогенностью личностного развития и спецификой субъективного ранжирования ценностей, свойственной конкретному человеку [Савченко, Снегирева 2017]. Отдельные исследователи идут еще дальше и изучают коррупционную личность в категориях «биотической трилемматики» [Юрьев 2008].

Некоторые авторы анализируют коррупционное поведение в рамках социологической дихотомии «личность - группа», рассматривая взаимозависимость индивидуального восприятия коррупции отдельной личностью и окружением, в котором личность находится [Рассадовская 2018].

Отдельная группа авторов заостряет внимание на криминологической характеристике личности сотрудников правоохранительных органов, совершающих коррупционные деяния [Бочарникова, Диденко, Михайлова 2012]. Большое значение придается анализу факторов [Савченко, Снегирева, Устинкин 2016] и мотивов [Сторчилова 2009] коррупционного поведения.

Таким образом, изучение коррупционной личности в последние годы ведется достаточно активно, однако сравнительные исследования вопросов восприятия коррупционной личности различными социальными (профессиональными и возрастными) общностями ни в отечественной, ни в зарубежной эмпирической исследовательской практике не проводились. Это в определенной мере объясняет актуальность эмпирического исследования, проведенного авторами данной статьи.

Цель исследования. Опросное исследование с рабочим названием «Мое личное отношение к коррупционерам» было проведено с целью изучения социально-групповых дифференциаций в общественном восприятии личности коррупционера.

Характеристика выборки. Анкетный опрос проводился в четырех выборках. Первая выборка - действующие офицеры полиции: 164 человека 23-52 лет из регионов Приволжского федерального округа: Нижнего Новгорода и Нижегородской обл., Республики Мордовия, Самарской, Кировской обл., Пермского края. Вторая выборка - люди гражданских профессий из городов ПФО (Нижний Новгород, Дзержинск, Киров, Пермь, Саранск, Чебоксары, Саратов, Самара): 132 человека в возрасте от 23 до 54 лет. Третья выборка сформирована из 143 будущих сотрудников полиции - курсантов и слушателей 18-22 лет, обучающихся на 2-4-м курсах Нижегородской академии МВД России. Четвертая выборка представлена 139 студентами гражданских вузов Нижнего Новгорода (от 18 до 22 лет, 2-4-й курсы).

Таким образом, выборки были распределены по двум пересекающимся плоскостям: возрастной и профессиональной. Выборки № 2 и № 4 можно обозначить как гражданские, внешние по отношению к работе органов правопорядка. Выборки № 1 и № 3 можно считать ведомственными, поскольку они включают сотрудников полиции, действующих и будущих.

Первую и вторую выборки можно считать взрослыми, т.к. в них вошли лица, уже получившие образование и осуществляющие трудовую или служебную деятельность. Третью и четвертую выборки, в свою очередь, можно назвать молодежными.

Результаты опроса и их обсуждение. Респондентам были представлены утверждения, характеризующие варианты их возможного отношения к личности коррупционера. Опрашиваемым предлагалось оценить соответствие каж- 
дого утверждения их собственному мнению о коррупционерах по 3-балльной шкале: (1) «да» (да, это так); (2) «возможно», (3) «нет» (это не так).

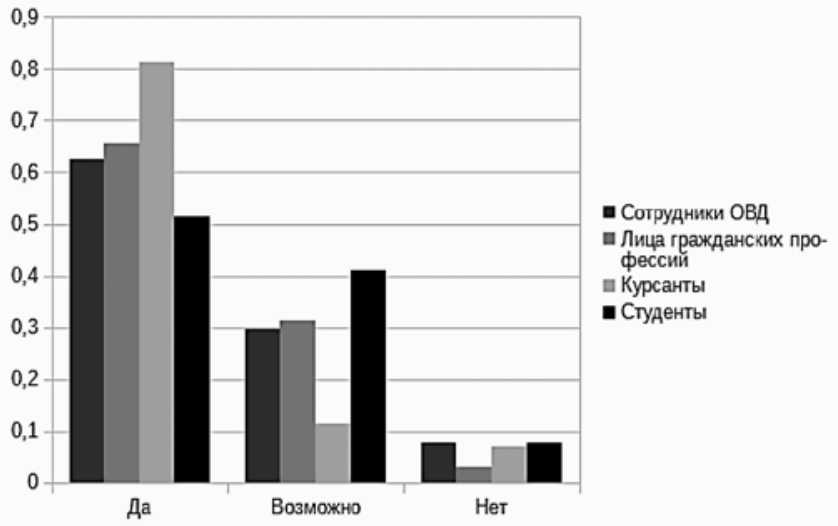

Рисунок 1. Степень согласия респондентов с утверждением: «Отношусь к коррупционерам с ненавистью. Они бессовестно наживаются на потребностях других людей»

Как видно из диаграммы на рис. 1, наибольшая степень неприязни к коррупционерам наблюдается в среде курсантов $-81,40 \%$, в то время как их ровесники из гражданских вузов относятся к коррупционерам скорее нейтрально. Такое различие можно объяснить тем, что проблема коррупции профессионально ближе курсантам и в вузах МВД целенаправленно формируется антикоррупционный стандарт поведения. Во «взрослых» выборках обнаруживается относительное единство мнений. В целом, во всех респондентских выборках преобладает негативное отношение к коррупционеру. Однако мы полагаем, что ответы на данный вопрос не дают нам полного представления о нюансах, которые, как мы полагаем, все же могут наблюдаться в отношении людей к личности коррупционера. Именно поэтому респондентам были заданы дополнительные вопросы.

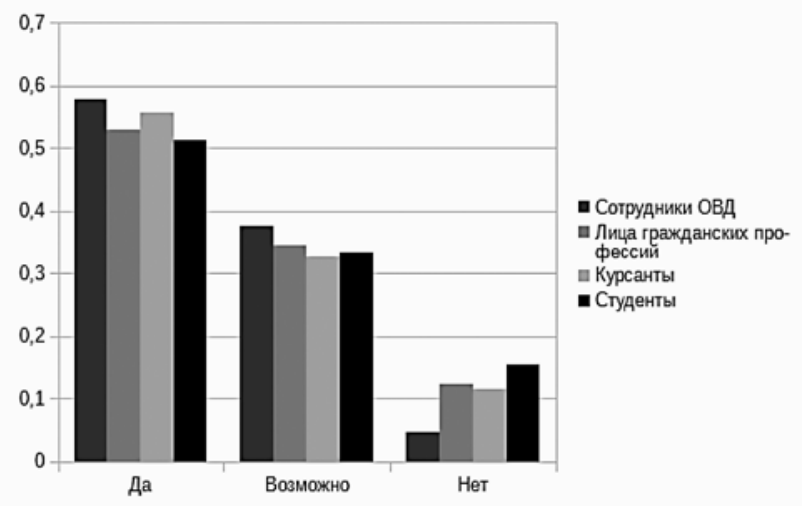

Рисунок 2. Степень согласия респондентов с утверждением: «Осуждаю коррупционеров. Но в то же время понимаю, что есть преступления гораздо страшнее коррупционных» 
Как видно из диаграммы на рис. 2, респонденты практически единодушны, полностью (в среднем по всем выборкам - 55\%) или частично (около $35 \%$ по всем выборкам) соглашаясь с утверждением: «Осуждаю коррупционеров. Но в тоже время понимаю, что есть преступления гораздо страшнее коррупционныХ». И все же следует отметить, что среди сотрудников ОВД число не разделяющих такое мнение примерно в 3 раза меньше, чем во всех других выборках. По-видимому, определенной части сотрудников в силу своих служебных обязанностей действительно приходилось видеть преступления «гораздо страшнее коррупционных».

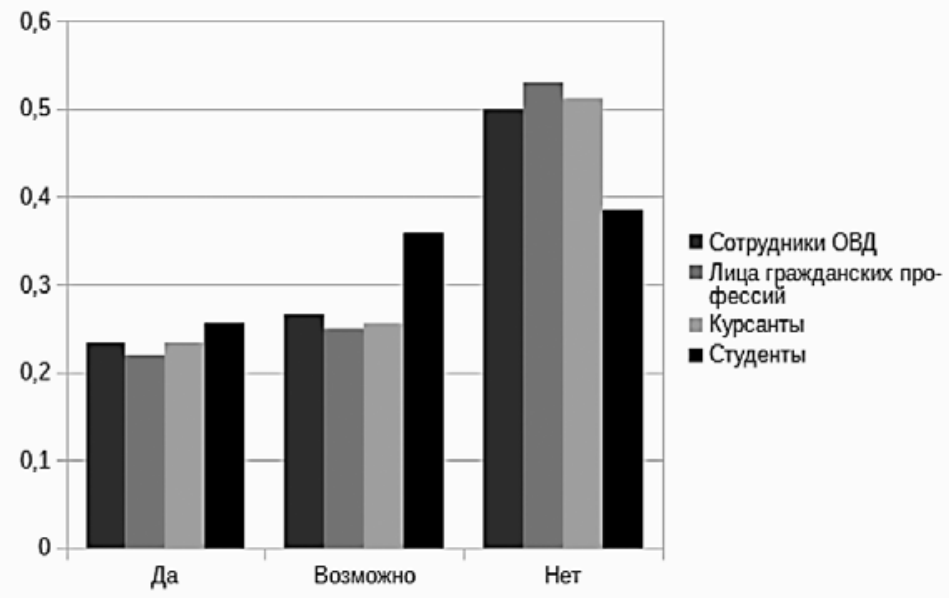

Рисунок 3. Степень согласия респондентов с утверждением: «Коррупционер - слабый человек, не устоявший перед соблазном. Осуждаю и жалею одновременно»

Данные, представленные на рис. 3, не дают нам представления о какой-либо дифференциации мнений между выборками. Во всех выборках мнения распределились примерно одинаково. Около 50\% опрошенных в каждой выборке не склонны жалеть не устоявшего перед соблазном коррупционера. Вместе с тем в каждой категории опрошенных примерно 1/4 относятся к коррупционерам амбивалентно - с осуждением и жалостью, полагая, что коррупционер - всего лишь слабый человек, не устоявший перед соблазном. Полученные данные позволяют предположить, что примерно для каждого четвертого человека в нашем обществе, будь он совсем молодым или зрелым, сотрудником правоохранительной сферы или представителем гражданской профессии, характерны свойственные христианской морали прощение и жалость по отношению к людям неустойчивым перед соблазном, к слабым духом. В знаменитой фразе из Евангелия от Матфея (гл. 5, ст. 3) «Блаженны нищие духом, ибо их есть Царство Небесное» под «нищими духом» изначально понимались люди негордые, смирившиеся с судьбой. Однако уже многие столетия в обыденном дискурсе под «нищими духом» подразумевают людей безвольных, слабохарактерных, зависимых и, по христианской традиции, сочувствуют им.

Если в ответах на предыдущий вопрос мы наблюдали определенное сходство в мнениях респондентов из различных категорий, то оценка утверждения: «Слабый человек, не устоявший перед примером коллег-коррупционеров. Осуждаю его и жалею одновременно», - напротив, обнаружила зримые противоречия (рис. 4). Более того, противоречия обнаружились как внутри профес- 


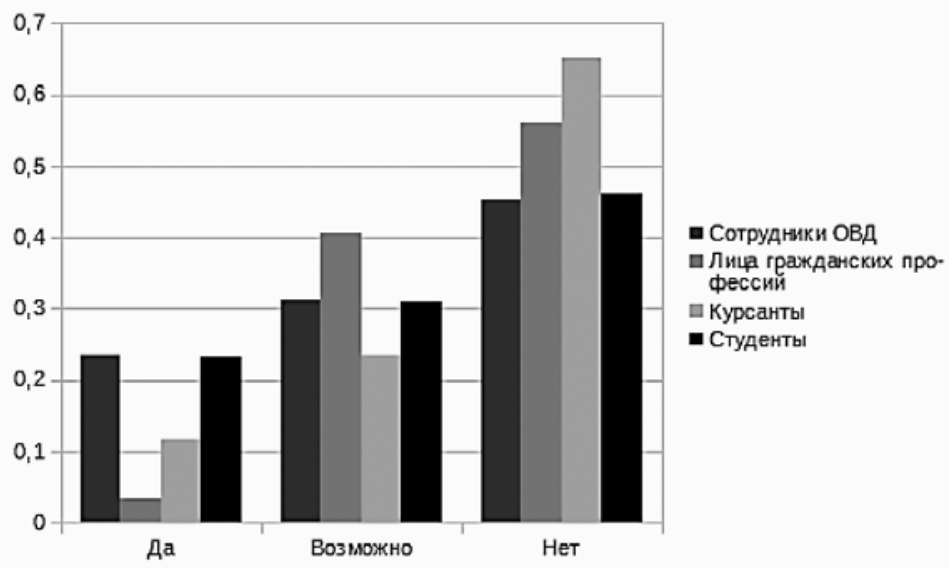

Рисунок 4. Степень согласия респондентов с утверждением: «Слабый человек, не устоявший перед примером коллег-коррупционеров. Осуждаю его и жалею одновременно»

сиональных выборок («ведомственных» и «гражданских»), так и возрастных. Например, больше половины сотрудников ОВД (54\%) разделяют подобное мнение полностью $(23,40 \%)$ или частично $(31,30 \%)$. В то же время курсанты наиболее категоричны их всех четырех выборок: 65,00\% из них ни при каких условиях не готовы сочувствовать коррупционеру, втянутому в коррупционную среду. Между тем мнения сверстников - курсантов и студентов - почти совпадают с мнениями офицеров полиции: $54 \%$ студентов полностью $(23,20 \%)$ или частично $(30,80 \%)$ согласны с обсуждаемым утверждением. Что касается лиц гражданских профессий, то они в своем большинстве не намерены жалеть слабохарактерного коррупционера, и в этом их позиция наиболее близка к позиции курсантов. Такой разброс во мнениях на первый взгляд кажется бессистемным и странным, однако ему можно найти объяснение.

Осуждающая и одновременно сочувственная позиция многих офицеров полиции по отношению к слабовольному коррупционеру является таковой потому, что им известны случаи, когда человек не по причине внутренней порочности, а в силу вынужденности или внутренней неустойчивости не смог противостоять коррумпированной профессиональной среде.

Сходство в позиции сотрудников ОВД и студентов является только количественным и имеет качественно различную природу. Так, для студентов проблема коррупции, вполне очевидно, является не самой актуальной. Студенты смотрят мало телевизионных программ, погружены в мир реального и виртуального общения со сверстниками. Они не хотят быть категоричными, потому что категоричность сегодня непопулярна. Их отношение к коррупционерам это позиция стороннего наблюдателя.

Люди гражданских профессий не склонны прощать коррупционеру слабоволие и слабохарактерность. Многие представители гражданских профессий получают представление о коррупции из телепрограмм и телефильмов, в которых некоторые аспекты обсуждаемого феномена представлены в гипертрофированном виде. Многие представители гражданских профессий убеждены, что, если человек попадает в коррупционную профессиональную среду, ему нужно эту среду менять. Не случайно они скорее простят человеку неустойчивость перед соблазном, нежели перед коррупционной средой. 
Устойчивая твердая осуждающая позиция курсантов по отношению к коррупционерам обусловлена, как уже указывалось, антикоррупционной направленностью образовательного процесса в ведомственном вузе.

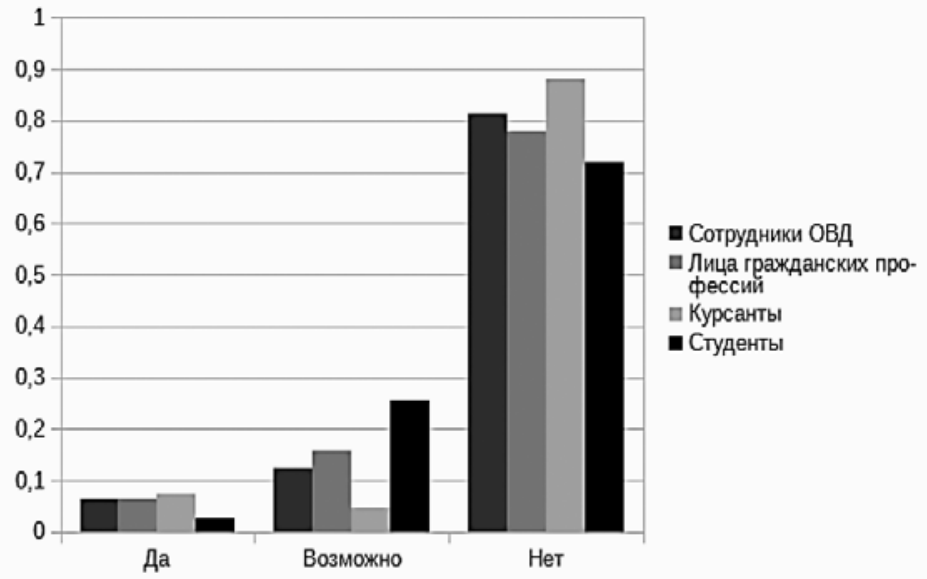

Рисунок 5. Степень согласия респондентов с утверждением: «Отношусь к коррупционерам с пониманием. Всем нужны деньги. Кто как может, тот так и зарабатывает»

В этом контексте достаточно примечательно, что индивида, ставшего коррупционером в силу духовной слабости и неустойчивости, многие готовы так или иначе простить (не переставая осуждать при этом). При этом человека, сделавшего сознательный выбор в пользу коррупционной активности как способа зарабатывания денег, представители всех респондентских групп в подавляющем большинстве безоговорочно осуждают (см. рис. 5). Но и здесь в силу уже обозначенной тенденции лидируют курсанты, выражая наиболее непримиримую позицию в отношении коррупционеров.

Диаграмма, представленная на рис. 6, иллюстрирует в какой-то степени процесс личностной рефлексии и механизм переноса. Утверждение, представленное в заголовке рисунка, на глубинном уровне трансформируется в вопрос индивида к самому себе: «А как бы повел себя я, если бы занимал должность, предоставляющую определенные возможности?»

Так, 60,5\% курсантов убеждены, что ни при каких условиях не воспользовались бы своим служебным положением в корыстных целях. Многие представители других целевых выборок засомневались и поэтому дали ответ: «возможно» (около 40\% по всем выборкам). «Как бы поступил я?»- очевидно, это тот самый вопрос, который время от времени должен задавать себе каждый при психологическом анализе явлений социально-правовой действительности.

Неожиданные результаты были получены при анализе утверждения: «Сочувствую ему (коррупционеру), хотя и не оправдываю. Коррупционер несчастный человек, которого финансовые проблемы заставляют идти на преступление» (рис. 7). Здесь выборки разделились по профессиональному признаку. Среди курсантов и сотрудников ОВД такого сочувствия не испытывают соответственно $60,5 \%$ и $64 \%$, в то время как среди студентов и представителей гражданских профессий такой показатель составил 79,5 и 78\% соответственно. Объяснить это можно только тем, что курсанты в ходе образовательного процесса, офицеры полиции - в процессе осуществления профессиональных обя- 


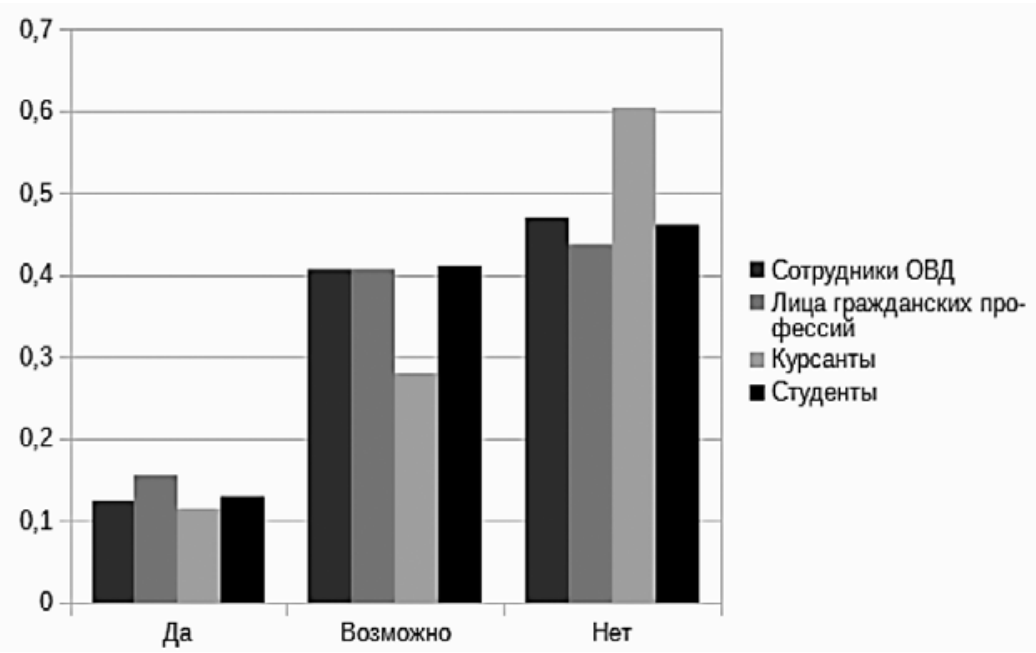

Рисунок 6. Степень согласия респондентов с утверждением: «Коррупционер - обычный человек, не хуже и не лучше остальных, в силу обстоятельств занимающий должность, предоставляющую определенные возможности. В таких обстоятельствах стать коррупционером может каждый»

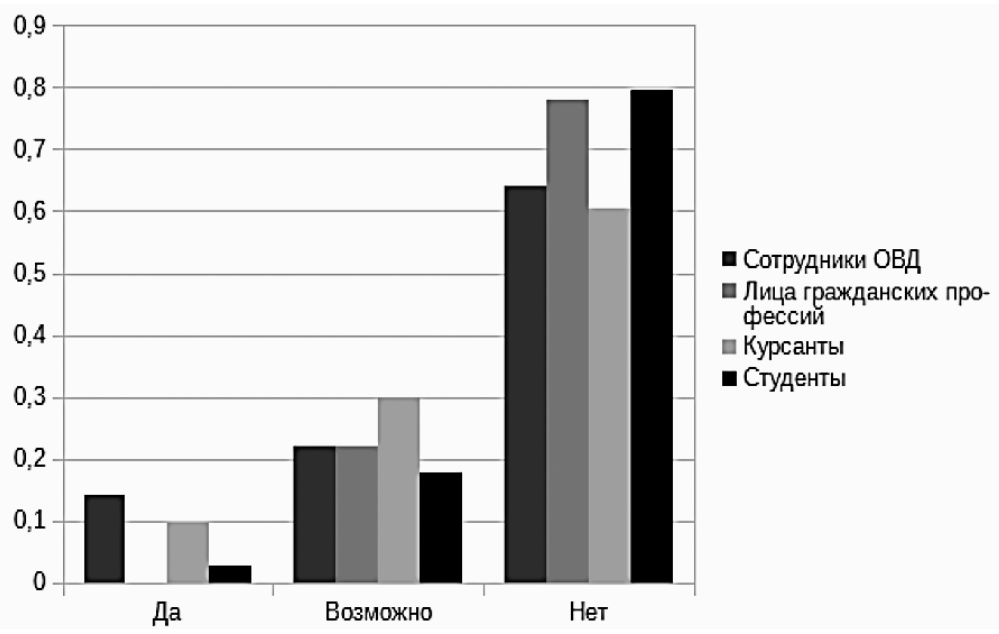

Рисунок 7. Степень согласия респондентов с утверждением: «Сочувствую ему, хотя и не оправдываю. Коррупционер - несчастный человек, которого финансовые проблемы заставляют идти на преступление»

занностей имели возможность ознакомиться с примерами, когда трудная жизненная ситуация, острая потребность в деньгах толкают человека на преступление, в данном случае коррупционное.

Можно ли посочувствовать (не оправдывая) человеку, чьи родственности подстрекают его к коррупционным деяниям? Как видно из диаграммы на рис. 8, очень немногие готовы к сочувствию такого рода. При этом не исключено, что сотрудники ОВД лично сталкивались со случаями, когда «неплохой от природы человек» шел, например, на поводу у алчной супруги и совершал деяние коррупционного характера. Поэтому число офицеров полиции, совершенно не 


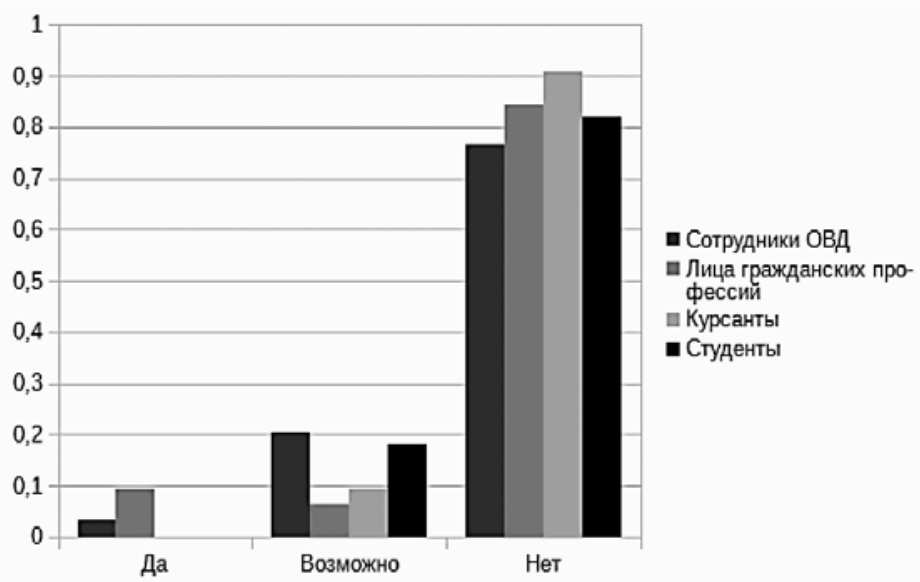

Рисунок 8. Степень согласия респондентов с утверждением: «Коррупционер - добродушный человек, которого алчные родственники (дети, супруги) подстрекают к противозаконным деяниям. Пусть это не оправдание, но ему можно посочувствовать»

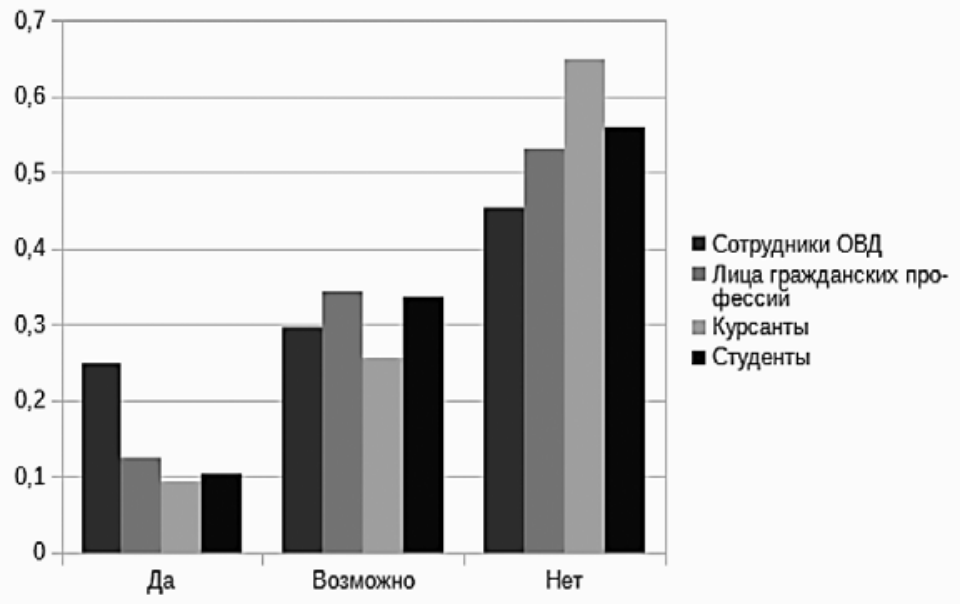

Рисунок 9. Степень согласия респондентов с утверждением: «Я не сформировал для себя определенное отношение к коррупционерам»

согласных с тем, что коррупционер может оказаться чересчур добродушным человеком, не способным отказать алчным родственникам, несколько ниже, чем в других выборках $(76,50 \%)$.

Прежде чем приступить к анализу данных, представленных в диаграмме на рис. 9, предлагаем вспомнить ответы на вопрос анкеты, касавшийся ненависти к коррупционерам. Как мы помним, абсолютное большинство респондентов, с незначительными различиями в выборках, признавались в ненависти к коррупционерам.

Больше половины представителей «гражданских» выборок (56\% студентов и 53,1\% представителей гражданских профессий) уверены, что уже сформировали свое отношение к коррупционерам. Однако ответы на предыдущие вопросы позволяют думать, что эта позиция все же является не окончательной. 
Подавляющая часть курсантов (65\%) считают свою позицию по отношению к коррупционеру достаточно твердой, однако не исключено, что эта позиция каким-либо образом трансформируется во время их будущей практической деятельности.

Весьма важно, что больше половины офицеров полиции - людей, которые знакомы с проблемой коррупционной преступности, - признали утверждение: «Я не сформировал для себя определенное отношение к коррупционерам» верным (25\%) или почти верным (29,70\%). На наш взгляд, только профессионально и личностно зрелые люди могли дать настолько искренний ответ. Подчеркнем, речь идет не об отношении к коррупции, а именно к личности коррупционера. В данном случае сомнение говорит не об отсутствии собственного мнения, а о глубокой рефлексивной позиции: в данном случае - о позиции сотрудников правоохранительных органов. Глубокая рефлексивная позиция свидетельствует о поиске новых, наиболее эффективных подходов к противодействию коррупции и, главное, к ее профилактике и предупреждению.

Заключение. Эмпирическое исследование, проведенное среди сотрудников органов внутренних дел, лиц гражданских профессий, курсантов и студентов, показало, что в восприятии личности коррупционера различными профессиональными и возрастными группами наблюдаются как сходство, так и отличия. Такие наблюдения, бесспорно, значимы для организации антикоррупционной деятельности, и в особенности для профилактики коррупционного поведения.

Мы полагаем, что проведенное исследование имеет как общетеоретическую, так и прикладную, методическую ценность и будет полезно всем, кто неравнодушен к проблеме коррупции в российском обществе.

\section{Список литературы}

Бочарникова Л.Н., Диденко К.В., Михайлова И.А. 2012. Личностные характеристики сотрудника органов внутренних дел, совершающего коррупционные преступления. - Вестник Белгородского юридического института МВД России. № 2(20). C. 52-56.

Горобова В.В. 2015. Коррупция и нравственные пороки личности. Гуманитарные ведомости ТГПУ им. Л.Н. Толстого. № 2(14). С. 41-45.

Попов Е.А. 2012. Коррупция и культура человека. - Евразийский юридический журнал. № 3(46). С. 63-66.

Рассадовская А.В. 2018. Влияние социального капитала на восприятие коррупции в группе. - Вестник Нижегородского университета им. Н.И. Лобачевского. Сер. Социальные науки. № 2(50). С. 16-24.

Савченко И.А. 2015. Гражданское общество в дискурсивном измерении. Власть. Т. 23. № 5. С. 122-126.

Савченко И.А., Снегирева Л.А. 2017. Коррупционная направленность личности в эмпирическом измерении. - Юридическая наука и практика: Вестник Нижегородской академии МВД России. № 1(37). С. 78-83.

Савченко И.А., Снегирева Л.А., Устинкин С.В. 2016. Факторы формирования коррупциогенной личности: иерархия и экспертные оценки. - Bлacmb. № 12. C. 177-182.

Савченко И.А., Снегирева Л.А., Устинкин С.В. 2018. Причины коррупции в кросс-методологическом измерении. - Власть. Т. 26. № 5. С. 35-39.

Сторчилова Н.В. 2009. Особенности криминологической характеристики личности сотрудников органов внутренних дел, совершающих коррупционные преступления. - Теория и практика общественного развития. № 3-4. С. 275-279.

Юрьев Г.П. 2008. Биоэтическая трилемматика пикто-феромонного поведения человека, коррупции и дедовщины. - Информационные войны. № 4(8). С. 72-83. 
SAVCHENKO Irina Aleksandrovna, Dr.Sci. (Soc.), Professor of the Chair of Philosophy, Sociology and the Theory of Social Communication, Dobroljubov State Linguistics University of Nizhny Novgorod (31a Minina St, Nizhny Novgorod, Russia, 603155); Professor of the Chair of Philosophy, Nizhny Novgorod Academy of Ministry of Internal Affairs of the Russian Federation (3 Ankudinovskoye Highway, Nizhny Novgorod, Russia, 603144; teosmaco@rambler.ru)

SNEGIREVA Lyudmila Anatol'evna, Cand.Sci. (Psych.), Associate Professor; Head of the Chair of Philosophy, Nizhny Novgorod Academy of Ministry of Internal Affairs of the Russian Federation (3 Ankudinovskoye Highway, Nizhny Novgorod, Russia, 603144; sla_sq@mail.ru)

USTINKIN Sergei Vasil'evich, Dr.Sci (Hist.), Dean of the Faculty of International Relations, Economics and Management; Professor of the Chair of International Relations and Political Science, Dobroljubov State Linguistics University of Nizhny Novgorod (31a Minina St, Nizhny Novgorod, Russia, 603155); Director of Volga Branch of the Federal Center of Theoretical and Applied Sociology, Russian Academy of Sciences (4 Holodny Lane, Nizhny Novgorod, Russia, 603000; sv.ustinkin@gmail.com)

\title{
CORRUPTION PERSONALITY IN PERCEPTION OF PROFESSIONAL AND AGE SOCIAL GROUPS
}

\begin{abstract}
The paper presents an analysis of the results of an empirical study aimed at studying the public perception of the identity of a corrupt official. The authors show that among a large number of works whose authors study various aspects of the phenomenon of corruption, one can find research focused on understanding the nature of a corrupt personality, including from the point of view of its perception by other people. At the same time, neither Russian no Western science study the distinctions, which can be observed in the attitudes towards corrupt officials in various social groups. The authors of this article conduct a comparative analysis of the perception of a corrupt personality by representatives of various age and professional groups: they are law enforcement officers and persons of civil professions, cadets of educational institutions of the Ministry of Internal Affairs of Russia, and university students. They attempt to explain the similarities and differences in the assessments of the identity of a corrupt official by different social groups.
\end{abstract}

Keywords: corruption, corruption behavior, corruption personality, social group, internal affairs officers, persons of civil professions, cadets 